\title{
Creating 'obesogenic realities'; do our methodological choices make a difference when measuring the food environment?
}

Thomas Burgoine ${ }^{1 *}$, Seraphim Alvanides ${ }^{2}$ and Amelia A Lake ${ }^{3}$

\begin{abstract}
Background: The use of Geographical Information Systems (GIS) to objectively measure 'obesogenic' food environment (foodscape) exposure has become common-place. This increase in usage has coincided with the development of a methodologically heterogeneous evidence-base, with subsequent perceived difficulties for inter-study comparability. However, when used together in previous work, different types of food environment metric have often demonstrated some degree of covariance. Differences and similarities between density and proximity metrics, and within methodologically different conceptions of density and proximity metrics need to be better understood.

Methods: Frequently used measures of food access were calculated for North East England, UK. Using food outlet data from local councils, densities of food outlets per 1000 population and per $\mathrm{km}^{2}$ were calculated for small administrative areas. Densities (counts) were also calculated based on population-weighted centroids of administrative areas buffered at 400/800/1000m street network and Euclidean distances. Proximity (street network and Euclidean distances) from these centroids to the nearest food outlet were also calculated. Metrics were compared using Spearman's rank correlations.

Results: Measures of foodscape density and proximity were highly correlated. Densities per $\mathrm{km}^{2}$ and per 1000 population were highly correlated $\left(r_{s}=0.831\right)$. Euclidean and street network based measures of proximity $\left(r_{s}=0.865\right)$ and density ( $r_{s}=0.667-0.764$, depending on neighbourhood size) were also highly correlated. Density metrics based on administrative areas and buffered centroids of administrative areas were less strongly correlated $\left(r_{s}=0.299-0.658\right)$.

Conclusions: Density and proximity metrics were largely comparable, with some exceptions. Whilst results suggested a substantial degree of comparability across existing studies, future comparability could be ensured by moving towards a more standardised set of environmental metrics, where appropriate, lessening the potential pitfalls of methodological variation between studies. The researchers' role in creating their own obesogenic 'reality' should be better understood and acknowledged.
\end{abstract}

Keywords: Obesogenic Environments, Foodscape, Methods, Exposure, Density, Proximity

\section{Introduction}

With the scale of the obesity epidemic ever increasing, there has been a recent and growing body of literature that suggests an environmental contribution of the food environment (foodscape) to dietary choices and obesity [1]. Food choices are made in context, within our respective foodscapes at micro and macro levels [2,3], and hold the potential to shape our behaviour. Research studies of

\footnotetext{
* Correspondence: tb464@medschl.cam.ac.uk

'UKCRC Centre for Diet and Activity Research (CEDAR), Box 296, Institute of Public Health, Forvie Site, Robinson Way, University of Cambridge,

Cambridge CB2 OSR, UK

Full list of author information is available at the end of the article
}

the food environment at the neighbourhood level have reported a variety of outcomes and have employed a range of methodologies [4]; many use Geographical Information Systems (GIS) to objectively measure the potential environmental influence on individuals' behaviours and overall health.

Practically, there has been increased attention paid to the ways in which environmental foodscape attributes pertaining to weight can be modelled using GIS [5]. Many studies of the 'obesogenic' [1] food environment utilise measures of density and proximity to measure food 'access'. Food outlet density is a measure designed

\section{Biomed Central}


to reflect the range or 'intensity' of any given food outlet type, in terms of the number of food outlets present around an individual [6,7]. Food outlet proximity is usually the distance to the nearest food outlet, with distance inversely related to utilisation [8,9]. Charreire et al. [4] systematically demonstrated the pervasiveness of density and proximity metrics in the published literature. However, the substantive differences between density and proximity metrics, beyond their theoretical distinction, are under-studied. Do areas with high food outlet density always offer residents food outlets at a closer proximity? Could ensuing analyses be simplified by using only one foodscape exposure metric? Two previous studies have concluded that both measures "tell a consistent story about food access" $[9,10]$, questioning the extent to which both measures are necessary, considering the effort required to compute multiple metrics and the problems associated with covariance in later analyses; more research is required to better understand this issue.

Moreover, precise definitions of density and proximity vary between studies. For example, when evaluating proximity, studies have used straight line (Euclidean) distance [11-13], or street network distance to the nearest food outlet [14-24], which in reality may be very different distances. Despite this, only one US study has addressed differences in food outlet proximity estimates when using either street network or Euclidean approaches [9]; no international comparison has been provided in the literature to date. Other common approaches to estimating food outlet access include: studies using food outlet density per head of population [6,10,16,25-37], whilst others, density per square unit of area [26,28,38]; all of these studies have calculated exposure within some previously defined administrative boundary (census tracts, electoral wards and so on), whereas others have chosen to use GIS to buffer study participants [39-49], or where these locations are unknown, the centroids of these administrative areas (geographic- or population-weighted) [11], creating 'neighbourhoods' at a range of spatial scales (for example $400 / 800 / 1000$ ), which here we proprietarily refer to as 'pseudo-individual' neighbourhoods; using the latter approach, or again the exact locations of study participants, both Euclidean [11,39-45], and street network based definitions of neighbourhood have been employed $[49,50]$. Table 1 gives more detail about these common approaches to estimating food outlet access, but a recent methodological review comprehensively described the wide range of approaches to calculating density and proximity taken in the literature [4], including others, such as novel inverse distance weighting (IDW) approaches to calculating food access [48], that have been used less frequently in the literature to date. This methodological heterogeneity is potentially problematic, yet the extent to which it may contribute to a lack of comparability between foodscape research findings is unknown. A methodologically heterogeneous evidence-base is often simply the bi-product of development within a science over time, and may not be associated with grave implications for inter-study comparability. However, it is nonetheless important to continue to work to understand the possible consequences of this evolution. Recent studies have begun to employ multiple metrics of foodscape exposure, and have considered the implications of methodological nuance between types of density metrics and between types of proximity metrics $[9,39,40,51]$. However direct comparisons of metrics were either not made or the range of metrics assessed was limited. In one study [9], the two density metrics compared represent only two of the many methodological options available for objectively capturing food outlet exposure. A more comprehensive comparison of types of density and proximity metrics is required in order to understand what implications our methodological choices have in determining estimates of geographic access to food outlets.

Our study used GIS to compute a range of commonly employed foodscape density and proximity metrics in the North East of England, UK. The research had two principle aims. Firstly, to compare food outlet density and proximity metrics to one another using correlation analysis. Secondly, to compare different metrics of density and proximity in a sensitivity analysis, to determine whether methodological differences in the calculation of each type of metric might serve to limit comparability between existing research findings. Comparisons made were as follows: 1) administrative area density per 1000 population vs. administrative area density per $\mathrm{km}^{2} ; 2$ ) administrative area densities vs. 400/800/1000 m 'pseudoindividual' densities; 3) 400/800/1000 m 'pseudo-individual' densities, when using either Euclidean vs. street network buffers; 4) Euclidean vs. street network measures of proximity from population-weighted LSOA centroids. These four binaries of methodological comparison represent common-sense comparisons, and have been suggested as necessary in empirical work and systematic reviews in the literature $[4,11,51-53]$.

\section{Methods}

The study area for this research was the former North East Government Office Region, UK, an environmentally heterogeneous area covering $8676 \mathrm{~km}^{2}$. Locations of food outlets $(n=14,454)$ were sourced from local councils $(n=23)$ under Freedom of Information (FOI) requests (for more details on the FOI Act 2000, see http://www.legislation.gov.uk/ukpga/2000/36/data.pdf). This data represents the most accurate secondary source of food outlet location data in the UK $[54,55]$. Food outlets were categorised into 'Food Bought-' $(\mathrm{n}=3793)$ and 'Food Consumed Out of the Home' $(\mathrm{n}=10,661)$ types, based on the likely site of food preparation [56]; see Burgoine [57] for full details. 
Table 1 Food environment exposure metrics compared in this study, and precedent for their use in the literature

\begin{tabular}{|c|c|c|}
\hline Variable & Description & 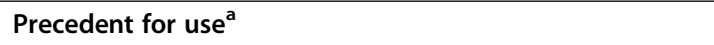 \\
\hline \multicolumn{3}{|l|}{ LSOA } \\
\hline \multicolumn{3}{|l|}{ Density per: } \\
\hline 1000 population & $\begin{array}{l}\text { Density of food outlets per } 1000 \\
\text { population/per km², per LSOA }\end{array}$ & $\begin{array}{l}\text { O'Dwyer \& Coveney [25] | Maddock [26] | Mehta \& Chang [27] } \\
\text { Ball et al. [6] | Moore \& Diez Roux [28] | Chou et al. [29] } \\
\text { Mobley et al. [30] | Simmons et al. [31] Sturm \& Datar [32] } \\
\text { Black et al. [33] | Powell et al. [34] | Burgoine et al. [10] } \\
\text { Cummins et al. [35] | Reidpath et al. [36] | Macdonald et al. [37] } \\
\text { Macdonald et al. [16] }\end{array}$ \\
\hline $\mathrm{km}^{2}$ & & Block et al. [38] | Maddock [26] | Moore and Diez Roux [28] \\
\hline
\end{tabular}

LSOA centroid
$\begin{aligned} & \text { Density per buffer at: } \\ & 400 \mathrm{~m} \text { Euclidean radius }\end{aligned}$
$\begin{aligned} & \text { Counts of food outlets within 400/800/ } \\ & 800 \mathrm{~m} \text { Euclidean radius }\end{aligned}$
$\begin{aligned} & 1000 \mathrm{~m} \text { Euclidean radius buffers from } \\ & \text { population-weighted centroids of LSOA }\end{aligned}$

1000 m Euclidean radius

$400 \mathrm{~m}$ Street Network

$800 \mathrm{~m}$ Street Network

1000 m Street Network

Proximity using:

Euclidean distance

Street network distance
$1000 \mathrm{~m}$ Euclidean radius buffers from

population-weighted centroids of $\mathrm{LSOA}$ street network buffers from population-

weighted centroids of LSOA

Euclidean or street network distance $(\mathrm{m})$ from LSOA population-weighted centroids

\author{
Austin et al. ${ }^{c}[39] \mid$ Currie et al. ${ }^{c}[40]$ \\ Austin et al. ${ }^{c}$ [39] | Jeffery et al. ${ }^{\mathrm{c}}$ [41] | Laraia et al..$^{\mathrm{c}}$ [42] \\ Timperio et al.' [43] | Currie et al. ${ }^{c}$ [40] \\ Spence et al. ${ }^{c}[44]$
}

Apparicio et al. [11] | Smoyer-Tomic et al. [45] | Seliske et al.' [46]

Smith et al..$^{c}[47]$

Smoyer-Tomic et al. [50] | Harrison et al. [48]

Larsen \& Gilliland ${ }^{c}$ [49] | Seliske et al. [46]

Counts of food outlets within 400/800/1000 m

Apparicio et al. [11] | Winkler et al. [12] | Bodor et al. [13] to nearest food outlet
Zenk et al. [14] | Pearce et al. [15] | Macdonald et al. [16] | Smith et al. [17] Pearce et al. [18] | Sharkey et al. [19] | Pearce et al..$^{d}$ [20] Sharkey \& Horel [21] | Block et al.' [24] | Burdette \& Whitaker [22] | Frank et al.' [23]

\footnotetext{
${ }^{a}$ Methodologically similar, not necessarily using LSOAs; using imperial or metric measurements; geographic- or population-weighted centroids.

${ }^{\mathrm{b}}$ Manhattan block distance used as an alternative to street network distance.

'Buffer sizes employed around known home or school address.

dUsed travel time rather than travel distance.
}

For brevity, only the geographies of 'Food Bought Out of the Home' outlets were considered in this study ('supermarkets,' 'convenience,' 'discount' and 'department' stores, plus 'specialist' retailers (butchers, delicatessens, bakers, fishmongers, confectioners, greengrocers, health, organic, fair trade, artisan, sweet and oriental stores)); results not presented showed no differences in findings when analysing 'Food Consumed Out of the Home' outlets ('restaurants', 'pubs', pizzerias', 'fast food', 'cafés'/ coffee shops', 'takeaways', 'sandwich shops', 'bakers - retail, 'hotels', 'entertainment,' 'health and leisure,' 'novelty stores' and 'pharmacies'). Using lookup tables from GeoConvert (http://geoconvert.mimas.ac.uk/), food outlet locations were mapped based on their postcodes using ArcGIS 9.3 (ESRI Inc., Redlands, CA). Recent precedent has been set in the literature for geocoding at the postcode level in the UK [47].

Details of the exposure metrics deduced are shown in Table 1 (the 'Variable' column). Neighbourhood densities of food outlets were calculated per 1000 population (population data from the 2001 UK census) and per $\mathrm{km}^{2}$ within Lower Super Output Areas (LSOAs); these are small administrative areas (median size $0.49 \mathrm{~km}^{2}$ ), each containing roughly 1500 residents (available from UKBORDERS, http:// edina.ac.uk/census/). Densities (counts of food outlets) were also calculated within $400 \mathrm{~m}, 800 \mathrm{~m}$ and $1000 \mathrm{~m}$ Euclidean and street network buffers from the populationweighted centroids of LSOAs. We refer to these buffered LSOA centroids as 'pseudo-individual' neighbourhoods on the assumption that food access at this calculated location is representative of the rest of the LSOA. Street network data were provided by Ordnance Survey as part of their MasterMap Integrated Transport Network (ITN). Proximity, Euclidean and street network distance to the nearest food outlet, was also calculated from these populationweighted centroids. Precedent for the frequent use of each metric, is also shown in Table 1, informed by recent systematic review articles $[4,52,53,58]$, which should be referred to for a comprehensive review of the literature. The metrics compared and contrasted in this study represent those that have been widely employed in obesogenic environment studies to date.

\section{Statistical analysis}

Analyses were performed throughout using SPSS 17.0 (SPSS Inc., Chicago, 2006). Descriptive statistics (medians, interquartile ranges, and ranges) for our environmental metrics are presented first. As our exposure metrics were 
continuous variables, differences between density and proximity metrics, and within types of density and types of proximity metrics were assessed using correlation analyses. We used Spearman's rank correlations because the vast majority of our access metrics were not normally distributed, with their distributions tending to be positively skewed. When comparing density and proximity metrics directly, we present the inverse of the correlation co-efficient obtained. As higher proximity values actually relate to greater distances (worse access to the food outlet), this allows, for example, a positive co-efficient to be interpreted as greater density allied with greater proximity (less distance).

\section{Results}

Descriptive statistics for the exposure metrics created are shown in Table 2. The median number of food outlets per 1000 population was 0.8 , whilst the median number per $\mathrm{km}^{2}$ was 2.0. There was a linear increase in median access as neighbourhood buffer sizes increased, as expected, and more so for Euclidean than street network buffers (which tend to be smaller, as illustrated in Figure 1). Median Euclidean distance to the nearest food bought out of the home outlet was $239.8 \mathrm{~m}$, but $398.8 \mathrm{~m}$ when constrained to the street network, and with a much greater range.

\section{Density compared to proximity}

This section compares food outlet density and proximity measures throughout the study area. Table 3 shows Spearman's rank correlations between density and proximity exposure metrics (all $\mathrm{p}<0.001$ ). Two salient trends emerged: 1) relationships within categories of density/ proximity were moderately to strongly correlated in uniform directions (co-efficients ranging between 0.299 and 0.926 for density metrics (mean $r_{s}=0.615$ ); 0.865 for the relationship between proximity metrics); 2) relationships between categories of density/proximity were also similar, with co-efficients having positive signs (i.e. all measures of density are moderate to strongly positively correlated with measures of proximity, and vice versa).

\section{Heterogeneity within exposure metrics}

This section examines the extent to which methodological heterogeneity within exposure metrics may impact upon comparability between findings in the literature to date. We make four necessary comparisons, as outlined in the aims.

\section{Density per 1000 population vs. density per $\mathrm{km}^{2}$}

Correlation analysis (Table 3) showed that whether LSOA density of 'Food Bought-' outlets is calculated per 1000 population or per $\mathrm{km}^{2}$, both measures were correlated very strongly $\left(\mathrm{r}_{\mathrm{s}}=0.831, \mathrm{p}<0.001\right)$ giving similar impressions of food access throughout the study area.
Area level vs. 400/800/1000m 'pseudo-individual' level density Table 3 showed that only moderate/moderately-strong correlations existed between area level and 'pseudo-individual' level metrics, ranging between $r_{s}=0.299$ and $r_{s}=$ 0.658 . Whilst they are all significant $(p<0.001)$ and in the same positive direction, these correlations suggest that we could be less sure of comparing results across studies that utilise these different approaches. The specific degree to which this statement holds true was attenuated by the metric examined: area and 'pseudoindividual' metrics were more comparable at smaller Euclidean and street network buffer distances, largely decreasing in strength at $800 \mathrm{~m}$, and further still at $1000 \mathrm{~m}$. The more nuanced street network buffers of 'pseudo-individual' density were largely more comparable with area level metrics, however, the $400 \mathrm{~m}$ Euclidean buffer was the most similar $\left(r_{s}=0.549\right.$ for LSOA density per 1000 population, $\mathrm{r}_{\mathrm{s}}=0.658$ for LSOA density per $\mathrm{km}^{2}$, both $\mathrm{p}<0.001)$.

\section{Street network vs. Euclidean 400/800/1000m 'pseudo- individual' level density}

Correlation results (Table 3) showed that levels of 'pseudoindividual' density were similar whether using a Euclidean or street network approach (at the same distance), and increasingly so when accounting for larger neighbourhoods $\left(400 \mathrm{~m} \mathrm{r}_{\mathrm{s}}=0.667 ; 800 \mathrm{~m} \mathrm{r}_{\mathrm{s}}=0.769 ; 1000 \mathrm{~m} \mathrm{r}_{\mathrm{s}}=0.783\right.$, all $\mathrm{p}$ $<0.001)$. 400m Euclidean neighbourhood densities were however more strongly correlated with $800 \mathrm{~m}$ street network densities $\left(r_{\mathrm{s}}=0.764\right)$, and $800 \mathrm{~m}$ Euclidean densities with $1000 \mathrm{~m}$ street network densities $\left(r_{\mathrm{s}}=0.854\right)$.

\section{Street network vs. Euclidean proximity}

Results presented in Table 3 showed that 'Food Bought-' proximity was comparable when assessed via Euclidean and street network distances $\left(\mathrm{r}_{\mathrm{s}}=0.865, \mathrm{p}<0.001\right)$. Much like the similarity displayed between Euclidean and street network 'pseudo-individual' neighbourhoods, this finding suggested that there was a substantial degree of comparability between the two metrics.

\section{Discussion}

This paper contributes to obesogenic foodscape research in two ways. Firstly, measures of density and proximity were compared to assess the extent to which they represent different facets of the foodscape. These measures are theoretically distinct and commonly differentiated in the literature, and it has been argued that to use just one metric is to do a disservice to the range of ways in which environments may affect behaviour [11]. However, using both metrics may lead to multicollinearity issues in ensuing analyses, resulting from covariance between the two metrics. Further, opting for either of the two metrics may provide a 'shortcut' for researchers wishing to 
Table 2 Descriptive statistics for exposure metrics across administrative areas $(n=1656)$

\begin{tabular}{|c|c|c|c|c|c|}
\hline & & Median & Interquartile range & Minimum & Maximum \\
\hline \multirow[t]{8}{*}{ Density } & Per 1000 population & 0.8 & $0.0-2.0$ & 0.0 & 35.0 \\
\hline & Per km² & 2.0 & $0.0-6.2$ & 0.0 & 105.4 \\
\hline & Per 400m Euclidean buffer & 2.0 & $1.0-4.0$ & 0.0 & 40.0 \\
\hline & Per 800m Euclidean buffer & 7.0 & $3.0-12.0$ & 0.0 & 81.0 \\
\hline & Per 1000m Euclidean buffer & 10.0 & $5.0-18.0$ & 0.0 & 94.0 \\
\hline & Per 400m street network buffer & 0.0 & $0.0-2.0$ & 0.0 & 34.0 \\
\hline & Per $800 \mathrm{~m}$ street network buffer & 3.0 & $1.0-6.0$ & 0.0 & 63.0 \\
\hline & Per $1000 \mathrm{~m}$ street network buffer & 4.0 & $2.0-9.0$ & 0.0 & 80.0 \\
\hline \multirow[t]{2}{*}{ Proximity } & Euclidean distance & 239.8 & 141.6-379.7 & 6.1 & 8535.4 \\
\hline & Street network distance & 398.8 & $229.8-652.2$ & 0.2 & 17886.4 \\
\hline
\end{tabular}

employ only a single, representative metric of foodscape exposure. Indeed, correlation analyses presented here provided tentative evidence that these measures represent the foodscape in very similar ways, suggesting that neighbourhoods with high food outlet density were also those where residents live within closer proximity to food, supporting previous findings $[9,10]$. However, this study does not represent definitive evidence that this is always the case, and opposite results have been observed [11]. Furthermore, although incidental, at the very least each measure may be susceptible to a different level of measurement error [59]. For example, where food outlet location data is not totally comprehensive, measures of food outlet density may be more prone to error (systematic underestimation of exposure) than measures of proximity (which, by chance, may remain completely accurate).
Secondly, this paper evaluated the extent to which methodological heterogeneity in calculating an exposure metric (density or proximity) contributes to a lack of inter-study comparability in findings. To some extent, results here suggested that such criticisms may be unfounded: measures of proximity from population-weighted centroids were highly correlated when using Euclidean or street network distance, corroborating findings from the only one comparable previous US study [9]. In addition, measures of 'pseudo-individual' density using Euclidean or street network distances were nearly equal at similar geographical scales, as has also been found elsewhere [51,60], whilst becoming more similar at greater distances. Buffer distances beyond $1000 \mathrm{~m}$ have been used in the literature $[6,11,12,25]$ and we could therefore expect even greater convergence. This said, there was evidence to suggest that Euclidean

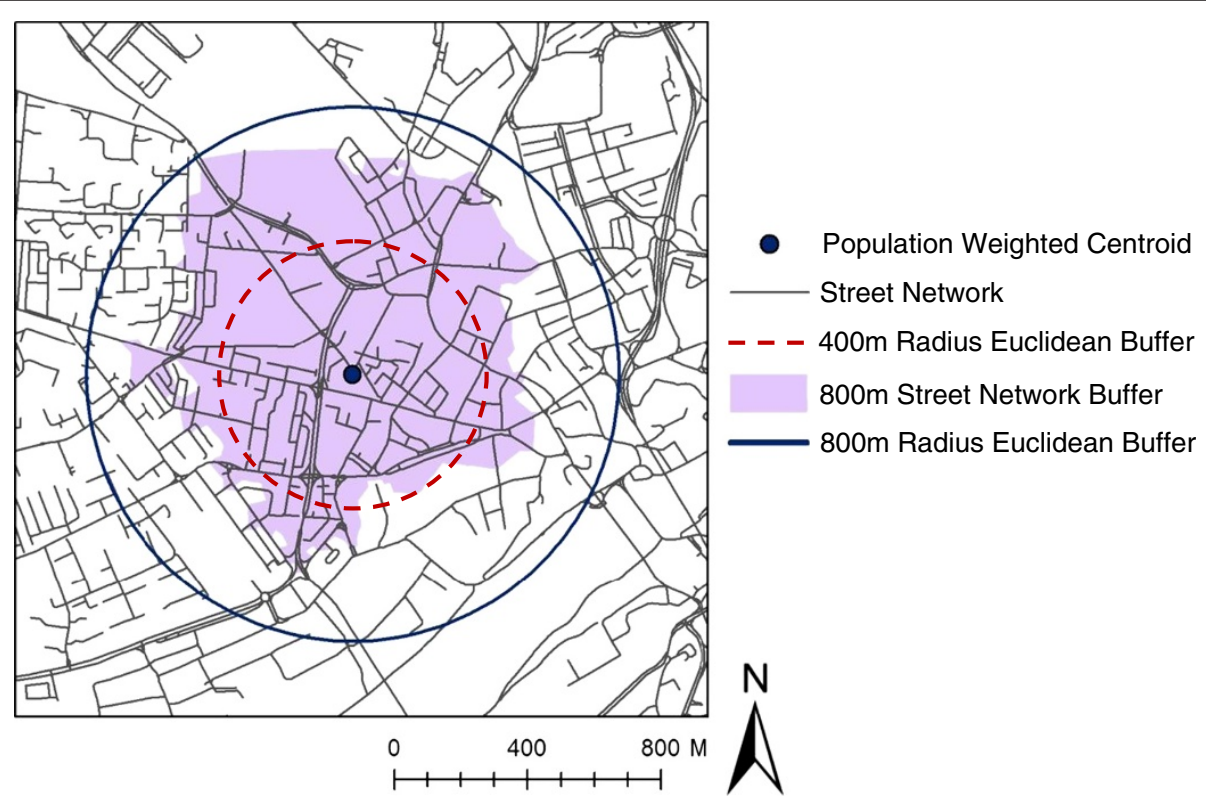

Figure 1 Comparing $800 \mathrm{~m} / 400 \mathrm{~m}$ Euclidean buffers to $800 \mathrm{~m}$ street network buffers. (c) Crown Copyright/database right 2012. An Ordnance Survey/EDINA supplied service. 
Table 3 Spearman's rank correlations between LSOA $(n=1656)$ density and proximity measures*

\begin{tabular}{|c|c|c|c|c|c|c|c|c|c|c|c|}
\hline & & \multicolumn{8}{|c|}{ Density } & \multicolumn{2}{|c|}{ Proximity } \\
\hline & & (1) & (2) & (3) & (4) & (5) & (6) & (7) & (8) & (9) & $(10)$ \\
\hline \multirow[t]{8}{*}{ Density } & Per 1000 population (1) & 1.000 & 0.831 & 0.549 & 0.354 & 0.299 & 0.494 & 0.474 & 0.434 & $0.512^{a}$ & $0.478^{a}$ \\
\hline & Per km² (2) & & 1.000 & 0.658 & 0.534 & 0.512 & 0.575 & 0.584 & 0.570 & $0.640^{a}$ & $0.579^{a}$ \\
\hline & Per 400m Euclidean buffer (3) & & & 1.000 & 0.653 & 0.586 & 0.667 & 0.764 & 0.718 & $0.720^{a}$ & $0.674^{a}$ \\
\hline & Per 800m Euclidean buffer (4) & & & & 1.000 & 0.926 & 0.445 & 0.769 & 0.854 & $0.474^{a}$ & $0.474^{a}$ \\
\hline & Per 1000m Euclidean buffer (5) & & & & & 1.000 & 0.411 & 0.695 & 0.783 & $0.442^{a}$ & $0.442^{a}$ \\
\hline & Per 400m street network buffer (6) & & & & & & 1.000 & 0.610 & 0.550 & $0.751^{\mathrm{a}}$ & $0.844^{a}$ \\
\hline & Per 800m street network buffer (7) & & & & & & & 1.000 & 0.918 & $0.589^{a}$ & $0.657^{a}$ \\
\hline & Per 1000m street network buffer (8) & & & & & & & & 1.000 & $0.543^{a}$ & $0.593^{a}$ \\
\hline \multirow[t]{2}{*}{ Proximity } & Euclidean distance (9) & & & & & & & & & 1.000 & 0.865 \\
\hline & Street network distance (10) & & & & & & & & & & 1.000 \\
\hline
\end{tabular}

* All results $p<0.001$.

${ }^{a}$ Inverse of correlation co-efficients presented to aid interpretation between, for example, greater density (higher exposure) and greater proximity (lower exposure).

buffers were most comparable to marginally larger street network buffers: 400m Euclidean buffers most strongly correlated with $800 \mathrm{~m}$ street network buffers and $800 \mathrm{~m}$ Euclidean buffers most strongly correlated with $1000 \mathrm{~m}$ street network buffers, confirming similar results from Thornton et al. [51]. This is likely to be because in general, Euclidean buffers result in a larger footprint, thus encapsulating more food stores, as illustrated in Figure 1. Statistical investigations also reported density per $\mathrm{km}^{2}$ and per 1000 population to be similar, inviting comparability across this methodological binary.

Measures of density at the area or 'pseudo-individual' level were only moderately correlated with one another, suggesting a limited extent to which findings across this divide should be compared. Unfortunately, this divide across metrics at the area or 'pseudo-individual' level separates two large bodies of academic work (Table 1), where studies have either located individuals within administrative area neighbourhoods, or created bespoke neighbourhood buffers around said individuals. Therefore, it may be of benefit to the field if a single (area or 'pseudo-individual') density metric were to be used in future research to maximise inter-study comparability, wherever possible. At the very least, studies should consider providing a rationale for their preference of approach to density calculation, whilst better and more fully acknowledging the assumptions and limitations inherent to either choice.

Beyond implying comparability across studies then, results suggest that there may only be small gains made from using street network distances for measures of 'pseudo-individual' density or proximity. This may be important when time or resources are at a premium or where street network data is unavailable. However, we disagree with Sparks et al. [9] who conclude that this equates to a reduced "computational burden on those wishing to use GIS methodology" - from which we infer that through not having to use more complex street network data, the usability of GIS methods is increased. It is argued here that there is a 'tipping point', where the value of using increasingly detailed metrics begins to diminish in relation to the computational effort required to create them. However, as we know little of this 'tipping point', and we should be mindful of scale differences (calculating street network availability may be more critical at $400 \mathrm{~m}$ radii than $1000 \mathrm{~m}$ radii, for example), we should always try to do the best that we can, even when confronted with technological challenges.

We argue here that we need to further consider how we can advance our methods and our metrics of exposure in objective studies of obesogenic food environments. Some studies have already sought to use measures of variety in relation to the food environment [6,11,32]; for example, the ratio of fast food to full service restaurants [32], designed to complement measures of density and proximity. Others have begun to use inverse distance weighted (IDW) measures of facility access, which to some extent ameliorate concerns arising over the relatively arbitrary definitions of 'neighbourhood' applied throughout the literature [48]. In reality however, it may never be possible, or even appropriate, to reach a point where even a wellconceived measure of food access can become a universal standard, suitable for use across all studies, as has been tentatively suggested [61]. Other methodological differences between studies - in statistical techniques, or in terms of study populations and their characteristics, which might vary between countries for example, and so on ensure that two studies will rarely, if ever, be completely comparable to one another. This does not detract however from the importance of attempting to understand the implications of such diversity, which is what we have begun 
to address here. A valid and reliable research evidence base, where differences in study findings can be fully understood and appreciated with respect to the methods used, from which conclusions about neighbourhood level effects on diet can be accurately drawn, will be absolutely critical in justifying neighbourhood interventions or pilot interventions designed to promote health, such as restricting the clustering of unhealthy food retailers.

This paper has a number of limitations. In this study we did not compare all foodscape metrics employed in the field to date; instead, we focused on many of the most commonly used metrics in order to relate to as much of the field as possible. Also, we did not investigate the entire foodscape here; different relationships may have been found for 'Food Consumed Out of the Home' outlets, although work not presented suggests this is not the case. There is also little compelling logic to suggest that the relationships tested here might be systematically biased according to the type of food outlet selected for study. Furthermore, the category of 'Food Bought Out of the Home' includes outlet types such as 'supermarkets' and 'convenience stores', density and proximity of which are frequently assessed in the literature. We did not have access to data on the exact locations of participants in this study, hence measures of proximity and some measures of density were calculated from administrative area population-weighted centroids, where we assumed at least one individual to live. This is an approach adopted in the literature where participant location data has not been available $[11,20]$, however we acknowledge that this could constitute a type of 'errorsin-variables' bias and that exposure throughout any given administrative area will vary [62], and would be likely to decrease away from population-weighted centroids. Our approach of using population-weighted centroids was at least consistent between areas. External validity in findings cannot be assumed, and we cannot rule out that results here may be particular to the North East of England, despite the large and heterogeneous study area, and the similarities between the study area and many other regions of the UK, notably in terms of its diverse socio-economic profile, with which we know foodscape exposure varies $[15,35,37]$. Lastly, we acknowledge that a greater density or proximity of food does not necessarily equate to more utilisation of these facilities. Considerations such as transport preferences, motivation to walk, economic factors, neighbourhood perceptions and so on will all contribute broadly to 'access' beyond purely a geographic perspective. We know for example that in Newcastle upon Tyne, in the North East of England, adults conducting their main supermarket shop on foot travel a median distance one-way of $510 \mathrm{~m}$, as compared to $2528 \mathrm{~m}$ for those with access to a car [63]. It is also worth considering that the vast majority of food environment exposure studies have tended to focus exclusively on residential neighbourhood exposure, despite the apparent necessity of accounting for time spent in wider 'activity spaces' [64], too. This said, our study compared foodscape metrics that are widely used in the field, rendering this research highly relevant, regardless of whether these previous studies conceived of access in a purely spatial sense or otherwise.

\section{Conclusions}

Our findings should be viewed in the context of creating different 'obesogenic realities' during the research design and analysis process. Despite occasional assertions to the objectivity of the "scientific approach", quantitative researchers are 'critical agents' in the GIS process $[65,66]$, and are required throughout their research to make a myriad of choices; the potential for these choices to impact upon results has been suggested elsewhere [67], and demonstrated to some extent here. In this way we create our own obesogenic realities and we should remain reflexive towards, and critical of these creations, in order to improve results and to chart a course for better future research. 'Researcher bias' has been well discussed in qualitative literatures, where data is often seen as being 'generated' rather than 'collected' as a reflection of the investigator's input into the research process $[68,69]$. Such issues of bias are less frequently discussed in quantitative discourse, particularly in relation to GIS, despite their apparent poignancy, although feminist critiques of GIS amongst others seek to increasingly understand the "exclusions, silences, and marginalizing $[s i c]$ power of our representations" [70-72]. Objective GIS studies are often based on the notion of 'technological determinism' [65,69], yet the extent to which this is possible is arguably limited. Leszczynski [73] warns against committing the 'ontic fallacy', whereby we unquestioningly accept our representation of reality to "mirror nature", and through failing to acknowledge the impact of the choices we make as researchers on the results we obtain, we risk falling into the ontological trap of what can truly be known. This paper demonstrates the need for such concern by contrasting an extensive range of environmental metrics and demonstrating that at least in some instances, the choices that we make do matter.

Ideally, our understanding of how individuals interact with their food environments should advance alongside available data sources and expertise, to allow similar but appropriate metrics of both density and proximity to be used between studies. This would facilitate the creation of a methodologically consistent evidence base, upon which to ascertain an objective environmental influence upon individuals, whilst not having to make excuses for methodological variation. Whilst desirable however, this may not be possible or indeed appropriate. Nevertheless, this study helps us to understand the current state of 
evidence in obesogenic environment research, by demonstrating that heterogeneity between most exposure metrics is not necessarily problematic.

\section{Competing interests}

The authors declare they have no competing interests.

\section{Authors' contributions}

The study design was jointly devised by TB, SA and AL. TB was responsible for data collection, and led on data analysis, in consultation with SA and AL. TB drafted the manuscript. All authors read and approved the final manuscript.

\section{Acknowledgements}

The data collection for this work was partly supported by an Economic and Social Research Council quota PhD studentship [ES/F021976/1]. The data analysis was undertaken by the Centre for Diet and Activity Research (CEDAR), a UK Clinical Research Collaboration (UKCRC) Public Health Research Centre of Excellence. Funding from the British Heart Foundation, Economic and Social Research Council, Medical Research Council, the National Institute for Health Research and the Wellcome Trust under the auspices of the UK Clinical Research Collaboration, is gratefully acknowledged. The digital maps used hold Crown Copyright from EDINA Digimap, a JISC supplied service. We are grateful to local councils throughout the study area for kindly supplying data to enable this work and to Ordnance Survey for supplying their MasterMap Integrated Transport Network (ITN) data.

\section{Author details}

${ }^{1}$ UKCRC Centre for Diet and Activity Research (CEDAR), Box 296, Institute of Public Health, Forvie Site, Robinson Way, University of Cambridge, Cambridge CB2 OSR, UK. ${ }^{2}$ Geography and the Built Environment, Ellison Building, Northumbria University, Newcastle upon Tyne NE1 8ST, UK. ${ }^{3}$ Centre for Public Policy and Health, School of Medicine, Pharmacy and Health, Wolfson Research Institute, Queen's Campus, Thornaby, Durham University, Stockton-on-Tees TS17 6BH, UK.

Received: 23 April 2013 Accepted: 23 June 2013

Published: 2 July 2013

\section{References}

1. Egger G, Swinburn B: An 'ecological approach' to the obesity pandemic. British Med J 1997, 315:477-480.

2. Lake AA, Townshend T: Obesogenic environments: exploring the built and food environment. Perspect Pub Health 2006, 126:262-267.

3. Townshend T, Lake AA: Obesogenic urban form: theory, policy and practice. Health Place 2009, 15:909-916.

4. Charreire H, Casey R, Salze P, Simon C, Chaix B, Banos A, Badariotti D, Weber C, Oppert J-M: Measuring the food environment using geographical information systems: a methodological review. Pub Health Nutr 2010, 13:1773-1785.

5. Brownson RC, Hoehner CM, Day K, Forsyth A, Sallis JF: Measuring the built environment for physical activity: state of the science. Am J Prevent Med 2009, 36:S99-S123.

6. Ball K, Timperio A, Crawford D: Neighbourhood socioeconomic inequalities in food access and affordability. Health Place 2009, 15:578-585.

7. Thornton LE, Pearce JR, Kavanagh AM: Using geographic information systems (GIS) to assess the role of the built environment in influencing obesity: a glossary. Int J Behavior Nutr Physic Act 2011, 8:1-9.

8. Van Meter EM, Lawson AB, Colabianchi N, Nichols M, Hibbert J, Porter DE, Liese AD: An evaluation of edge effects in nutritional accessibility and availability measures: a simulation study. Int J Health Geograph 2010, 9:1-30.

9. Sparks AL, Bania N, Leete L: Comparative approaches to measuring food access in urban areas: the case of Portland, Oregon. Urban Studies 2011, 48:1715-1737.

10. Burgoine T, Alvanides S, Lake AA: Assessing the obesogenic environment of North East England. Health Place 2011, 17:738-747.

11. Apparicio P, Cloutier M-S, Shearmur R: The case of Montreal's missing food deserts: evaluation of accessibility to food supermarkets. Int $J$ Health Geograph 2007, 6:1-13.
12. Winkler $E$, Turrell $G$, Patterson C: Does living in a disadvantaged area mean fewer opportunities to purchase fresh fruit and vegetables in the area? Findings from the Brisbane food study. Health Place 2006, 12:306-319.

13. Bodor JN, Rose D, Farley TA, Swalm C, Scott SK: Neighbourhood fruit and vegetable availability and consumption: the role of small food stores in an urban environment. Pub Health Nutr 2007, 11:413-420.

14. Zenk SN, Schultz AJ, Israel BA, James SA, Bao S, Wilson ML: Neighbourhood racial composition, neighbourhood poverty, and the spatial accessibility of supermarkets in metropolitan Detroit. Am J Pub Health 2005, 95:660-667.

15. Pearce J, Blakely T, Witten K, Bartie P: Neighbourhood deprivation and access to fast-food retailing: a national study. Am J Prevent Med 2007, 32:375-382.

16. Macdonald L, Ellaway A, Macintyre S: The food retail environment and area deprivation in Glasgow City, UK. Int I Behavior Nutr Physic Act 2009, 6:1-7.

17. Smith D, Cummins S, Taylor M, Dawson J, Marshall D, Sparks L, Anderson AS: Neighbourhood food environment and area deprivation: spatial accessibility to grocery stores selling fresh fruit and vegetables in urban and rural settings. Int J Epidemiol 2009, 39:277-284.

18. Pearce J, Hiscock R, Blakely T, Witten $K$ : The contextual effects of neighbourhood access to supermarkets and convenience stores on individual fruit and vegetable consumption. J Epidemiol Comm Health 2008, 62:198-201.

19. Sharkey JR, Horel S, Han D, Huber JC Jr: Association between neighborhood need and spatial access to food stores and fast food restaurants in neighborhoods of Colonias. Int J Health Geograph 2009, 8:1-17.

20. Pearce J, Witten K, Bartie P: Neighbourhoods and health: a GIS approach to measuring community resource accessibility. J Epidemiol Comm Health 2006, 60:389-395.

21. Sharkey JR, Horel S: Neighbourhood socioeconomic deprivation and minority composition are associated with better potential spatial access to the ground-truthed food environment in a large rural area. J Nutr 2008, 138:620-627.

22. Burdette HL, Whitaker RC: Neighbourhood playgrounds, fast-food restaurants, and crime: relationships to overweight in low-income preschool children. Prevent Med 2004, 38:57-63.

23. Frank LD, Glanz K, McCarron M, Sallis J, Saelens B, Chapman J: The spatial distribution of food outlet type and quality around schools in differing built environment and demographic contexts. Berkeley Plann J 2006, 19:79-95.

24. Block JP, Christakis NA, O'Malley AJ, Subramanian SV: Proximity to food establishments and body mass index in the Framingham Heart Study offspring cohort over 30 years. Am J Epidemiol 2011, 174:1108-1114.

25. O'Dwyer LA, Coveney J: Scoping supermarket availability and accessibility by socio-economic status in Adelaide. Health Promo J Australia 2006, 17:240-246.

26. Maddock J: The relationship between obesity and the prevalence of fast food restaurants: state-level analysis. Am J Health Promo 2004, 19:137-143.

27. Mehta NK, Chang WW: Weight status and restaurant availability: a multilevel analysis. Am J Prevent Medi 2008, 34:127-133.

28. Moore LV, Diez-Roux AV: Associations of neighbourhood characteristics with the location and type of food stores. Am J Pub Health 2006, 96:325-331.

29. Chou S-Y, Grossman M, Saffer H: An economic analysis of adult obesity: results from the Behavioural Risk Factor Surveillance System. J Health Econ 2004, 23:565-587.

30. Mobley LR, Root ED, Finkelstein EA, Khavjou O, Farris RP, Will JC: Environment, obesity, and cardiovascular disease risk in low-income women. Am J Prevent Med 2006, 30:327-332.

31. Simmons D, McKenzie A, Eaton $S$, Cox N, Khan MA, Shaw MA, Zimmet P: Choice and availability of takeaway and restaurant food is not related to the prevalence of adult obesity in rural communities in Australia. Int J Obes 2005, 29:703-710.

32. Sturm R, Datar A: Body mass index in elementary school children, metropolitan area food prices and food outlet density. Public Health 2005, 119:1059-1068.

33. Black JL, Macinko J, Dixon LB, Fryer GE Jr: Neighbourhoods and obesity in New York City. Health Place 2010, 16:489-499.

34. Powell LM, Auld C, Chaloupka FJ, O'Malley PM, Johnston LD: Association between access to food stores and adolescent body mass index. Am J Prevent Med 2007, 33:S301-S307.

35. Cummins SCJ, McKay L, Maclntyre S: McDonald's restaurants and neighbourhood deprivation in Scotland and England. Am J Preventi Med 2005, 29:308-310. 
36. Reidpath DD, Burns C, Garrard J, Mahoney M, Townsend M: An ecological study of the relationship between social and environmental determinants of obesity. Health Place 2002, 8:141-145

37. Macdonald L, Cummins S, Macintyre S: Neighbourhood fast food environment and area deprivation - substitution or concentration? Appetite 2007, 49:251-254

38. Block JP, Scribner RA, Desalvo KB: Fast food, race/ethnicity, and income: a geographic analysis. Am J Prevent Med 2004, 27:211-217.

39. Austin SB, Melly SJ, Sanchez BN, Patel A, Buka S, Gortmaker SL: Clustering of fast-food restaurants around schools: a novel application of spatial statistics to the study of food environments. Am J Pub Health 2005, 95:1575-1581.

40. Currie J, Della Vigna S, Moretti E, Pathania V: The effect of fast food restaurants on obesity. American Association of Wine Economists. Working Paper; 2009.

41. Jeffery RW, Baxter J, MCGuire M, Linde J: Are fast food restaurants an environmental risk factor for obesity? Int J Behavior Nutr Physic Act 2006, 3:1-6.

42. Laraia BA, Siega-Riz AM, Kaufman JS, Jones SJ: Proximity of supermarkets is positively associated with diet quality index for pregnancy. Prevent Med 2004, 39:869-875.

43. Timperio A, Ball K, Roberts R, Campbell K, Andrianopoulos N, Crawford D: Children's fruit and vegetable intake: associations with the neighbourhood food environment. Prevent Med 2008, 46:331-335.

44. Spence JC, Cutumisu N, Edwards J, Raine KD, Smoyer-Tomic K: Relation between local food environments and obesity among adults. BMC Public Health 2009, 9:1-6.

45. Smoyer-Tomic KE, Spence JC, Amrhein C: Food deserts in the prairies? Supermarket accessibility and neighbourhood need in Edmonton, Canada. Profession Geograph 2006, 58:307-326.

46. Seliske L, Pickett W, Rosu A, Janssen I: The number and type of food retailers surrounding schools and their association with lunctime eating behaviours in students. Int J Behavior Nutr Physic Act 2013, 10:1-9.

47. Smith D, Cummins S, Clark C, Stansfeld S: Does the local food environment around schools affect diet? Longitudinal associations in adolescents attending secondary schools in East London. BMC Public Health 2013, 13:1-10.

48. Harrison F, Jones AP, van Sluijs EMF, Cassidy A, Bentham G, Griffin SJ: Environmental correlates of adiposity in 9-10 year old children: considering home and school neighbourhoods and routes to school. Soc Sci Med 2011, 72:1411-1419.

49. Larsen K, Gilliland J: Mapping the evolution of 'food deserts' in a Canadian city: Supermarket accessibility in London, Ontario, 1961-2005. Int J Health Geograph 2008, 7:16-32.

50. Smoyer-Tomic KE, Spence JC, Raine KD, Amrhein C, Cameron N, Yesonovskiy V, Cutumisu N, Hemphill E, Healy J: The association between neighbourhood socioeconomic status and exposure to supermarkets and fast food outlets. Health Place 2008, 14:740-754

51. Thornton LE, Pearce JR, Macdonald L, Lamb KE, Ellaway A: Does the choice of neighbourhood supermarket access measure influence associations with individual-level fruit and vegetable consumption? A case study from Glasgow. Int J Health Geograph 2012, 11:1-12.

52. Black JL, Macinko J: Neighbourhoods and obesity. Nutrition Rev 2008, 66:2-20.

53. Feng J, Glass TA, Curriero FC, Stewart WF, Schwartz BS: The built environment and obesity: a systematic review of the epidemiologic evidence. Health Place 2010, 16:175-190.

54. Lake AA, Burgoine T, Greenhalgh F, Stamp E, Tyrrell R: The foodscape: classification and field validation of secondary data sources. Health Place 2010, 16:666-673.

55. Lake AA, Burgoine T, Stamp E, Grieve R: The foodscape: classification and field validation of secondary data sources across urban/rural and socio-economic classifications. Int J Behavior Nutr Physic Act 2012, 9:3-12.

56. Cummins S, Macintyre S: Food environments and obesity neighbourhood or nation? Int J Epidemiol 2006, 35:100-104.

57. Burgoine T: Collecting accurate secondary foodscape data: a reflection on the trials and tribulations. Appetite 2010, 55:522-527.

58. Caspi CE, Sorensen G, Subramanian SV, Kawachi l: The local food environment and diet: a systematic review. Health Place 2012, 18:1172-1187.

59. Moore LV, Diez-Roux AV, Nettleton JA, Jacobs DR: Associations of the local food environment with diet quality - a comparison of assessments based on surveys and geographic information systems. Am J Epidemiol 2008, 167:917-924.
60. Boone-Heinonen J, Gordon-Larsen P, Kiefe Cl, Shikany JM, Lewis CE, Popkin BM: Fast food restaurants and food stores: longitudinal associations with diet in young to middle-aged adults: the CARDIA Study. Arch Int Med 2011, 171:1162-1170.

61. Forsyth A, Schmitz KH, Oakes M, Zimmerman J, Koepp J: Standards for environmental measurement using GIS: toward a protocol for protocols. J Physic Act Health 2006, 3:241-257.

62. Fortney J, Rost K, Warren J: Comparing alternative methods of measuring geographic access to health services. Health Serv Outcomes Res Methodol 2000, 1:173-184.

63. White M, Bunting J, Williams L, Raybould S, Adamson A, Mathers J: Do 'food deserts' exist? A multi-level, geographical analysis of the relationship between retail food access, socio-economic position and dietary intake. Final Report to the Food Standards Agency; 2004.

64. Kestens $Y$, Lebel A, Daniel M, Thériault M, Pampalon R: Using experienced activity spaces to measure foodscape exposure. Health Place 2010, 16:1094-1103.

65. Kwan M-P: Is GIS for women? Reflections of the critical discourse in the 1990s. Gender Place Culture 2002, 9:271-279.

66. Chrisman N: Full circle: more than just social implications of GIS. Cartographica: Int J Geograph Info Geovisual 2005, 40:23-35.

67. Caspi CE, Kawachi I, Subramanian SV, Adamkiewicz G, Sorensen G: The relationship between diet and perceived and objective access to supermarkets among low-income housing residents. Soc Sci Med 2012, 75:1254-1262

68. Mason J: Qualitative researching. London: SAGE Publications Ltd; 1996.

69. Kvale S: Interviews: an introduction to qualitative research interviewing. London: SAGE Publications Ltd; 1996.

70. Kwan M-P: Feminist visualisation: re-envisioning GIS as a method in feminist geographic research. Ann Assoc Am Geograph 2002, 92:645-661.

71. Rose G: Visual methodologies: an introduction to the interpretation of visual materials. London: Sage; 2001.

72. Elwood S: Thinking outside the box: engaging critical geographic information systems theory, practice and politics in human geography. Geography Compass 2010, 4:45-60.

73. Leszczynski A: Poststructuralism and GIS: is there a 'disconnect'? Environ Plann D: Soc Space 2009, 27:581-602

doi:10.1186/1476-072X-12-33

Cite this article as: Burgoine et al:: Creating 'obesogenic realities'; do our methodological choices make a difference when measuring the food environment? International Journal of Health Geographics 2013 12:33.

\section{Submit your next manuscript to BioMed Central and take full advantage of:}

- Convenient online submission

- Thorough peer review

- No space constraints or color figure charges

- Immediate publication on acceptance

- Inclusion in PubMed, CAS, Scopus and Google Scholar

- Research which is freely available for redistribution

Submit your manuscript at www.biomedcentral.com/submit
C) Biomed Central 